\title{
Gender Representation and Cultural Value: The Comparison of Japanese and Indonesian Kit Kat Green Tea TV Commercials
}

\author{
Tia Saraswati, Universitas Airlangga
}

\begin{abstract}
Commercial functions not only to promote a product from the sales aspect, but also to image a product. Commercial even also depicts the gender representation. This study employs two objects, that is the TV commercial of Kit Kat Green Tea Otona (Japan) and Kit Kat Green Tea (Indonesia) since the purpose of this study is to reveal the gender representation and the cultural values that appear in both commercials. The method of the study is the descriptive qualitative with the approach of discourse analysis by Sara Mills. The findings are the TV commercial of Kit Kat Green Tea Otona depicts the dominance of patriarchal culture through the female actress, that when she feels disappointed, she will get help from a co-worker who is a man and she does not solve her own problem herself. She even enjoys the preferential treatment (being given Kit Kat Green Tea) from the man. On the other hand, Indonesian Kit Kat Green Tea commercial does not present female actress at all and even can be said to show male dominance. The male actor solves his own problem by eating Kit Kat available on his table and he can overcome his fear toward his boss. Moreover, the cultural values depicted in both commercials are Japanese cultural values such as bending over (ojigi), geisha, cherry blossom (sakura), and Japanese traditional instrument shamisen.
\end{abstract}

Keywords: gender; gender representation; Kit Kat Green Tea commercial; Sara Mills' discourse analysis

\section{Introduction}

Gender becomes a fascinating matter to talk about since when it is presented in media, the gender representation appeared is the representation formed by the media maker. One of the media with short duration but has high persuasive value and full of gender representation is commercial. Commercial as the mass communication media functions to promote a product and to narrate the advantages of the product. Moreover, according to Bungin (2008), commercial also has the duty to change a product into an image, and whatever imaging employed in a commercial, whether it is social class image, sexuality image, and so on, what is important is that the image will give the impact to the product. However, in the middle of a commercial imagery, commercial can also be said to represent gender bias with the dominance of male over female. As if to confirm that, Suwasana (2001) stated that commercial is the means of legitimizing ideological hegemony as well as the preservation of dominance of patriarchal ideology. One example of commercials with gender representation and patriarchal ideology is the TV commercial of chocolate wafer Kit Kat Green Tea which has the tagline Ada break, ada Kit Kat ("Have a break, have a Kit Kat") and is aired in Japan and Indonesia.

One of the variants of Kit Kat products is green tea which is made in Japan and also spread in Indonesia in different packaging. The tagline of Kit Kat commercial in Japan is fascinating, which is otona no amasa which means 'adult sweetness'. The highly-gendered product renders otona (adults) as the target consumers and it presents Kit Kat flavor whose sweetness is light, unlike other flavors of Kit Kat whose sweetness and milkiness are abundant. Related to otona, Krooand Matsumoto (2018) discussed in Discource and Communication journal about the products with otona label that they analyzed, that is Otona Black Kit Kat (dark chocolate), Otona Glico Chocolate, Heinz Pastas and Sapporo Beer which also form the femininity and masculinity representation. Starting from Krooand Matsumoto's (2018) study, this study attempts to see further how the commercial of similar product, that isKit Kat Green Tea commercial, is imaged by the commercial makers from two countries, that is Japan and Indonesia. More details, the problems that is attempted to be discussed is the gender 
representation in two commercials, that is the TV commercials of Kit Kat Green Tea from Japan and Indonesia. Then, the comparison of cultural values depicted in TV commercials of Kit Kat Green Tea from Japan and Indonesia is also attempted to be analyzed. It is considered that this study is required to be conducted since all this time, research with commercials as the object related to gender portrayal often use quantitative method with content analysis (Arima, 2003). The study with Japanese and Indonesian commercials conducted by Almierajati (2013) also employed similar method, which is content analysis. However, Almierajati (2013) did not specifically look at a certain product since she emphasized more on the factors utilized in the commercials to attract the audience. The results demonstrated that Indonesian commercial depicts durability, enjoyment, family, vain, youth, and so on, while Japanese commercial has the expensive, unique, maturity, morality, safety, and status characteristics. Thus, this study is conducted to enrich the diversity of media research, particularly the comparison of two commercials from different countries which advertise similar products.

\section{Method of the Study}

This study employs descriptive qualitative method by using the theory of discourse analysis by Sara Mills. Eriyanto (2001) mentioned that Sara Mills uses many discourse theories by emphasizing on female depiction in texts, such as novel, picture, photo, and news, which is related to the feminism discussion. The focal point in the perspective of feminist discourse is demonstrating that a text can be bias in representing women. Women are placed as the party who is guilty, cornered, and treated unfairly, so women are not depicted as the good figures. These are the things that Mills has mostly highlighted. Although Mills mostly highlighted the women representation, Mill's approach can also be employed on matters outside of women. The peculiarities of Mills' discussion are; 1) seeing how the actors' positions are depicted in a text, that is who becomes the subject and object of storytelling. The positions will determine the meaning that is enacted in the text, 2) also focusing on how the readers and writers are presented in a text.

The data of the study is the scenes from Japanese TV commercials of Kit Kat Green Tea Otona (2012) version and Indonesian TV commercial with similar product, that is Kit Kat Green Tea Kangen Sepatu (2016) version. The rationale of these objects' selection is although they have the similarity to promote the similar product, yet both commercials do the different imaging. The data is collected by: 1)downloading the video clips of Kit Kat Green Tea Otona and Kit Kat Green Tea Indonesia TV commercials from YouTube, 2) scrutinizing both commercials and cutting the scenes that depict gender representation (male and female) in the workspace and the cultural values of a country, 3) describing the values related to the discussion, that is the gender and cultural values, by using the discourse analysis by Sara Mills, 4) deducing the difference of gender representation and cultural values of both commercials, and 5) overall conclusion.

\section{Findings and Discussion}

The following will be the snapshots of the TV commercials of Kit Kat Green Tea in Japan and Indonesia which are analyzed with the discourse analysis framework by Sara Mills. 


\subsection{Kit Kat Green Tea Otona TV Commercial \\ 3.1.1 Scenes in Kit Kat Green Tea Otona TV Commercial}

Setting: The background of the spacious, classic-designed traditional Japanese house.

Table 1: Scenes in Kit Kat Green Tea Otona TV Commercial

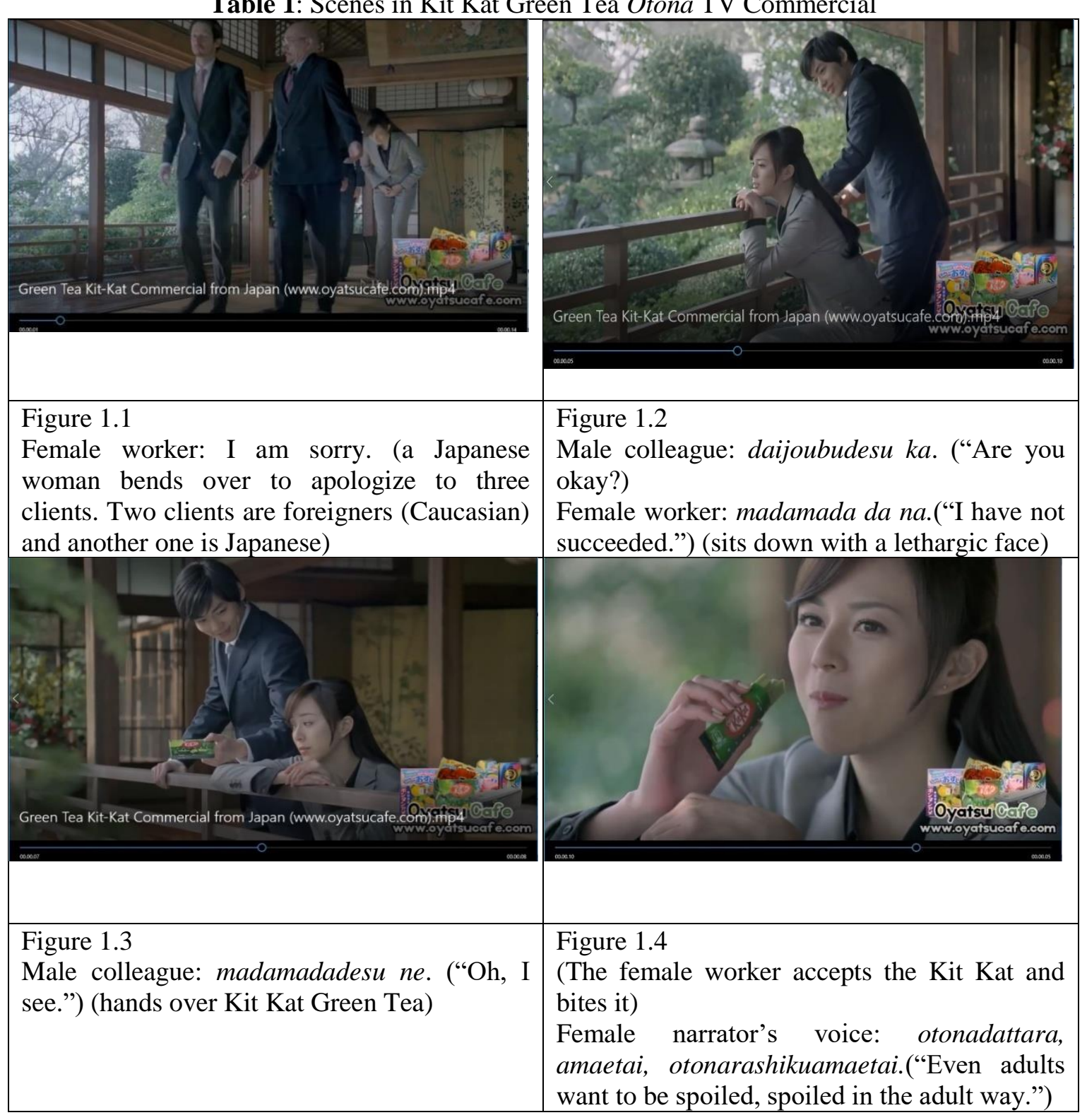


Table 1, cont.

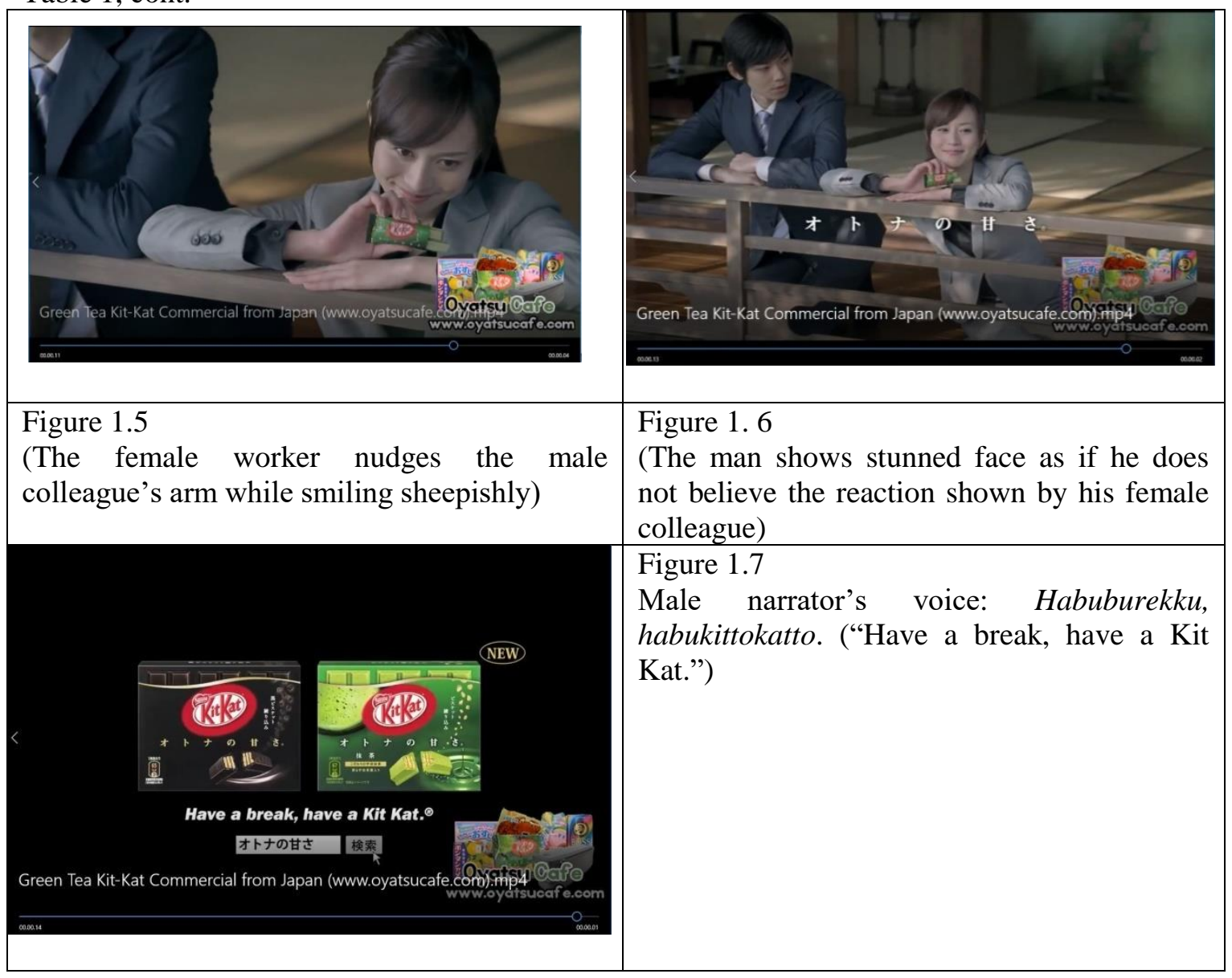




\subsubsection{Commercial Analysis with Sara Mills' Discourse Analysis}

After observing scene after scene in Kit Kat Green Tea Otona version carefully, then they are categorized and analyzed by employing the analysis framework from Sara Mills' discourse analysis.

Table 2: The Analysis Framework of Kit Kat Green Tea Otona TV Commercial

\begin{tabular}{|c|c|}
\hline Level & What is observed \\
\hline $\begin{array}{l}\text { Subject-Object } \\
\text { Position }\end{array}$ & $\begin{array}{l}\text { When seeing from the advertising storytelling, this commercial has two } \\
\text { main actors, that is the female worker (as the otona woman) and the } \\
\text { male worker (as the otona man). However, in this commercial, the } \\
\text { dominance of patriarchal culture is still visible throughout the overall } \\
\text { scenes where the woman is the one who apologizes when her party } \\
\text { makes a mistake, not her male colleague who is beside her.It can be seen } \\
\text { that the woman becomes the object (who is told) and the man becomes } \\
\text { the subject (who tells). The woman becomes the object since while } \\
\text { consuming Kit Kat, the female narrator's voice says that "Otonadattara, } \\
\text { amaetai. Otonarashikuamaetai" ("Even adults want to be spoiled, } \\
\text { spoiled in the adult way."). This indicates that the woman in the } \\
\text { commercial wants to get more attention from the opposite gender when } \\
\text { she feels down (being sad). She is not depicted to solve her own problem } \\
\text { solely with consuming Kit Kat Green Tea alone. Since there is the word } \\
\text { "spoiled", thus the woman here is purposely created to be relaxed from } \\
\text { the man who brings her Kit Kat.The dependence renders the woman in } \\
\text { this commercial to be placed as the party who has yet become a strong } \\
\text { individual and apart from men's help. An interesting point here is that } \\
\text { although from the overall storytelling the woman's image in this } \\
\text { commercial is depicted as the dominated party since she is considered } \\
\text { disappointing in her work and she is eventually entertained by her male } \\
\text { colleague, yet the woman here can actually show her happiness in the } \\
\text { feminine and 'naughty' way. She demonstrates it by nudging her } \\
\text { colleague's arm. The feminine way is what was stated by Kroo and } \\
\text { Matsumoto (2018) who investigated the commercial of Black Kit Kat } \\
\text { 'otona no amasa' assexual maturity by which the woman is not shy to } \\
\text { show her feeling with her tempting gesture. }\end{array}$ \\
\hline $\begin{array}{l}\text { Writer-Reader } \\
\text { Position }\end{array}$ & $\begin{array}{l}\text { For Mills (2001), most texts communicate to the readers or audience in } \\
\text { indirect way. Furthermore, text is interpreted as the result of negotiation } \\
\text { between the writer and the readers. The writer of this commercial text is } \\
\text { the commercial maker and the readers are the audience who watch this } \\
\text { commercial. In this commercial, the text seems to inform that if you } \\
\text { want to make your opposite gender feel relaxed and to spoil them, thus } \\
\text { you should give themKit Kat Green Tea otona no amasa. Moreover, this } \\
\text { text also states that the product is specifically to adult (both male and } \\
\text { female) which has special flavor (different from Kit Kat products } \\
\text { without otona label). Since the main character is a woman, thus the } \\
\text { dominant reading of the text is the audience is placed as the woman who } \\
\text { might feel the same way as the woman in the commercial, that is feeling } \\
\text { happy when someone suddenly gives a present and sympathy. However, } \\
\text { the writer (the commercial maker) still cannot get rid of gender } \\
\text { stereotype since the writer attempts to image (create an impression) that } \\
\text { women are the ones who need to be spoiled, not men. Men are the } \\
\text { solution givers, not the ones who accept solution from others (the } \\
\text { opposite gender). }\end{array}$ \\
\hline
\end{tabular}




\subsection{Kit Kat Green Tea Kangen Sepatu TV Commercial}

\subsubsection{Scenes in Kit Kat Green Tea Kangen Sepatu TV Commercial}

Setting: in the modern interior workspace. Each worker seems busy with their own work. Even so, the atmosphere is very eco-friendly since the scenery in front of the workspace is green trees.

Table 3: Scenes in Kit Kat Green Tea Kangen Sepatu TV Commercial

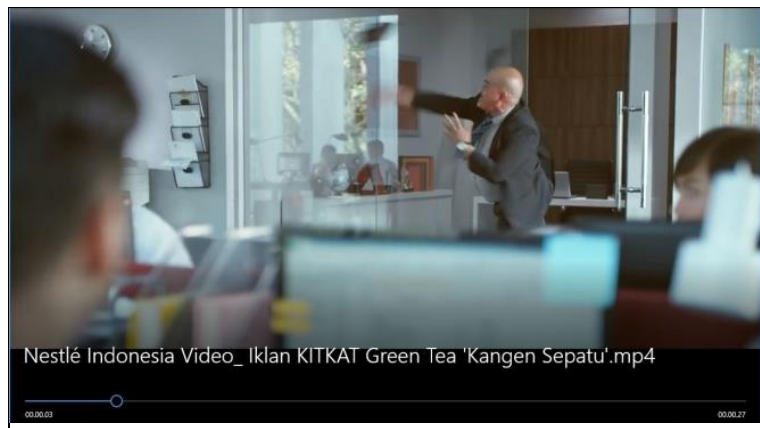

Figure 2.1

Male superior: Referensi aja kamu bagus ya. Kerja nggak becus! "Your reference is great. But your work isn't!") (screams while throwing his shoe to a male worker who is out of his office)

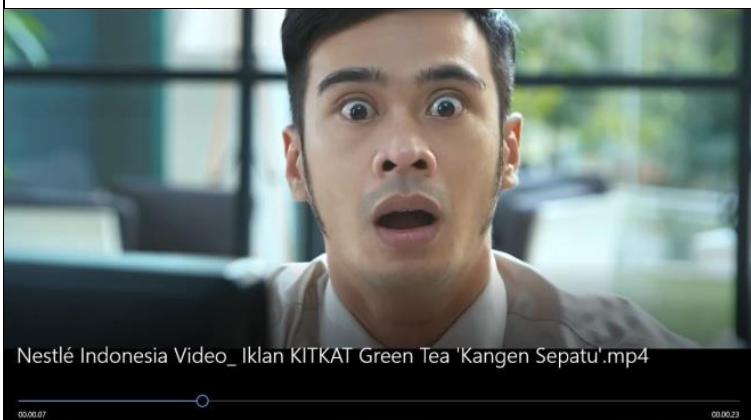

Figure 2.3

(The male worker seems shocked. His eyes are widened, and his mouth opens) (close-up shot)

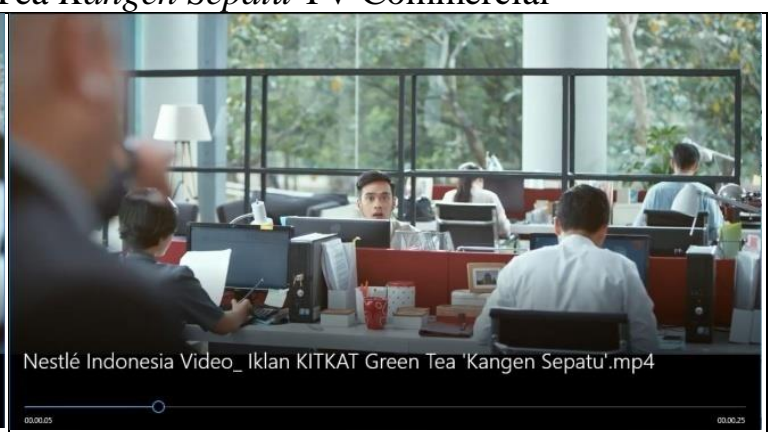

\section{Figure 2.2}

(Another male worker accidentally witnesses the incident and his gaze meets his superior's eyes)

Male superior: Kamu! Setengah jam lagi keruangan saya. ("You! Come to my office in half an hour.")

Figure 2.4
(To calm himself, he spontaneously takes a
pack of Kit Kat on his table)


Table 3, cont.

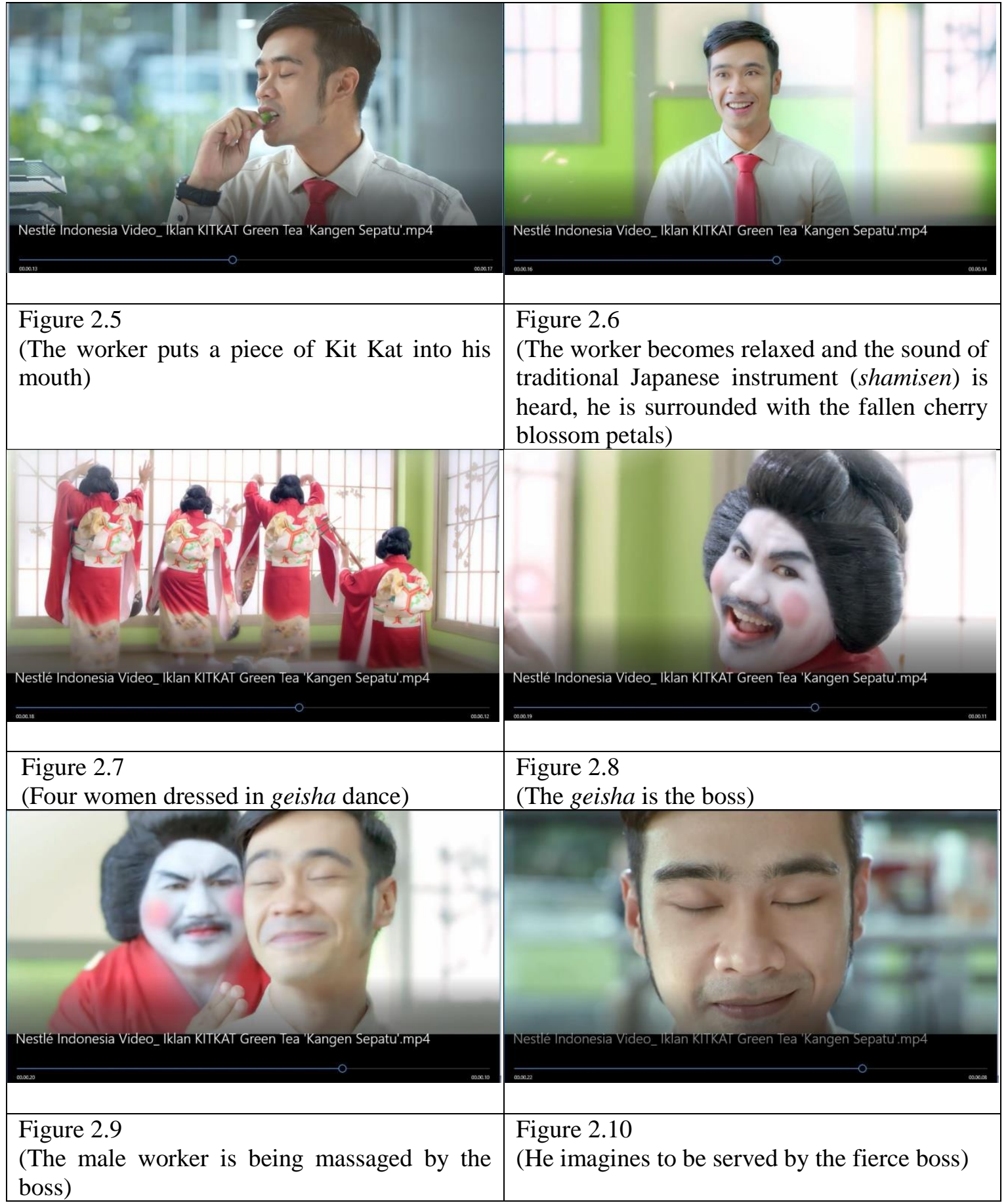


Table 3, cont.

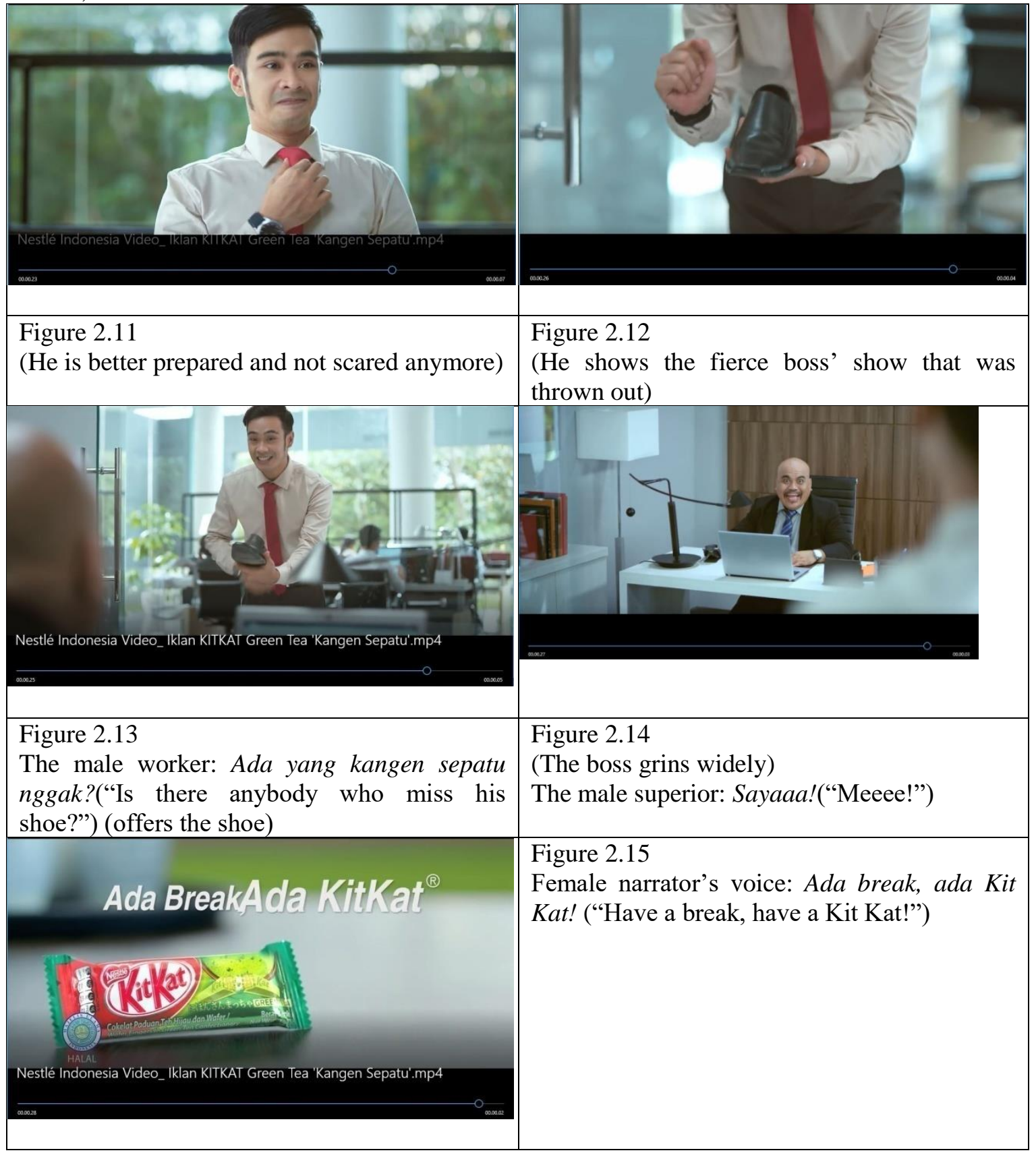




\subsubsection{Commercial Analysis with Sara Mills' Discourse Analysis}

The following is the categorization and analysis of scenes using the analysis framework from Sara Mills' discourse analysis.

Table 4: The Analysis Framework of Kit Kat Kangen Sepatu TV Commercial

\begin{tabular}{|l|l|}
\hline \multicolumn{1}{|c|}{ Level } & \multicolumn{1}{c|}{ What is observed } \\
\hline Subject-Object Position & $\begin{array}{l}\text { This commercial is played by two main actors, that is the male } \\
\text { worker as the subject (who tells) and the male superior as the object } \\
\text { (who is told). The gender depicted here is merely man, thus it can be } \\
\text { seen that the commercial maker (the writer) does not seem to want to } \\
\text { give any place to women. Whereas, as we can see nowadays, many } \\
\text { women take part in the workspace. Furthermore, the advertising story } \\
\text { model also employs humor elements that are depicted through the } \\
\text { worker's imagination when he bites Kit Kat and becomes relaxed so } \\
\text { the view in front of him is the fierce superior who changes into } \\
\text { geisha with the complete costume and dances and massages him as } \\
\text { well. In contrast to the Japanese version of Kit Kat commercial, this } \\
\text { commercial is not specified to otona (adults) and not addressed to any } \\
\text { specific gender, yet the target is wider (anyone, both young and old) } \\
\text { that can consume Kit Kat Green Tea. }\end{array}$ \\
\hline Writer-Reader Position & $\begin{array}{l}\text { The writer of this text is the commercial maker and the readers are } \\
\text { the commercial's audience. This commercial seems to want to } \\
\text { indirectly communicate to the audience that if they consume Kit Kat } \\
\text { Green Tea, they can feel relaxed and far from excessive fear. } \\
\text { Moreover, due to the storytelling from the worker side as the subject, } \\
\text { then the writer probably expects the readers or the audience, whose } \\
\text { jobs are workers, to also put their position to the actor's in the } \\
\text { commercial and can also consume Kit Kat Green Tea to solve their } \\
\text { problem like anxiety and so on. }\end{array}$ \\
\hline
\end{tabular}

\subsection{Comparison of Japanese Kit Kat Green Tea Otona dan Indonesian Kit Kat Green Tea TV Commercials}

Based on the data analysis of both commercials, it can be deduced that the comparisons of both commercials are from the aspects of:

1. Gender representation

In the commercial of Kit Kat Green Tea Otona from Japan, the gender representation seems equal, yet women are still depicted as the party who receive help from the opposite gender and still dominated by patriarchal culture. Meanwhile, in the commercial of Kit Kat Green Tea from Indonesia, women do not show up at all, thus this commercial seems to show male dominance. However, although the Japanese commercial of Kit Kat Green Tea is extremely gender bias since women seem to be depicted as the party to blame and the receiving party of the product, but the gesture demonstrated by the woman when accepting Kit Kat to her colleague depicts gender equality in terms of expressing feeling toward the opposite gender. This is related to the tagline of Japanese Kit Kat Green Tea, that is otona no amasa (adult sweetness).

\section{Cultural values}

The Japanese commercial of Kit Kat Green Tea depicts the Japanese cultural background such as the traditional place and Japanese manner like bending over (ojigi) when making a mistake to the others. The Indonesian commercial of Kit Kat Green Tea also depicts the Japanese cultural background, yet the background is mixed with humor element, thus the culture seems to not sacred and not graceful. The cultural values are merely to strengthen the 
identity of Kit Kat Green Tea as a Japanese product. The examples of the cultural values are geisha (played by the fierce superior), the fallen cherry blossom petals, and shamisen that is played by the fierce superior.

\section{Conclusion}

Based on the data and discussion results, the gender representation in the TV commercial of Kit Kat Green Tea Otona (Japan) and Kangen Sepatu episode (Indonesia) is as follows:

1. The TV commercial of Kit Kat Green Tea Otona depicts an otona (adult) woman figure who feels disappointed in her work and gets her happiness back due to the assistance of her male colleague. In this commercial, the woman enjoys the treatment from her colleague who gives her Kit Kat Green Tea, so it makes her relaxed and she seems to be spoiled by her colleague.

2.Meanwhile, the TV commercial of Kit Kat Green Tea Kangen Sepatu episode depicts male gender, that is the male worker, who succeeds in facing his own problem (his fear in being scolded by his fierce superior) by taking Kit Kat on his table and eating it himself. In this commercial, there is no woman actor and it can be said to show male dominance.

Then, the depiction of cultural values in the TV commercial of Kit Kat Green Tea Otona (Japan) and Kangen Sepatu episode (Indonesia) is as follows:

1. The TV commercial of Kit Kat Green Tea Otona depicts Japanese culture such as ojigi (bending over when making a mistake) and the Japanese traditional house as the background.

2. Meanwhile, the TV commercial of Kit Kat Green Tea Kangen Sepatu episode depicts Japanese culture such as geisha, spring with cherry blossom, and the Japanese traditional instrument shamisen.

\section{References}

Arima,A. N. 2003. Gender stereotypes in Japanese televisions advertisement. Sex Roles,49(1-2), 81-90.

Bungin, M. B. 2008. Konstruksi sosial media massa: kekuatan pengaruh media massa, iklan televisi dan keputusan konsumen serta kritik terhadap Peter L. Berger dan Thomas Luckmann. Jakarta: Kencana.

Eriyanto. 2001. Analisis wacana: Pengantar analisis teks media. Yogyakarta: LKIS Yoygakarta, Green Tea Kit Kat Commercial from Japan. Available athttp://youtube.com. (Accessed 28 May 2018).

Green Tea Kit Kat Commercial "Kangen Sepatu”. Available at http://youtube.com. (Accessed 28 May 2018).

Kroo, J., \& Matsumoto, Y. 2018. The case of Japanese otona 'adult': mediatized gender as marketing device. Discourse and Communication, 1-23.

Suwasana, A. A. 2001. Perspektif gender dalam representasi iklan. Nirmana,3(2), 83-96.

Almierajati, V. 2013. A cross-cultural content analysis of tv commercials in Indonesia and Japan: Standardization and adaptation in advertising. ISS \& $M L B, 24-26$. 